\title{
Lipid Metabolism in Acromegalic Patients before and after Selective Pituitary Adenomectomy
}

\author{
Hiroyasu TSUChiya, Toshio ONISHI, Heitaro MOGAMI* \\ AND Minoru IIDA
}

\begin{abstract}
Department of Epidemiology and Mass Examination for Cardiovascular Diseases, The Center for Adult Diseases, Osaka, and *Department of Neurosurgery, Osaka University Medical School
\end{abstract}

\begin{abstract}
Lipid metabolism was studied in 16 acromegalic patients who all underwent transsphenoidal selective pituitary adenomectomy (SPA). Before the operation, their serum lipid levels correlated with none of the basal levels of serum growth hormone $(\mathrm{GH})$, basal levels of plasma somatomedin-C (SM-C), fasting levels of plasma glucose (FPG), peak levels of plasma glucose $\left(\mathbf{P G}_{\mathrm{p}}\right)$ or basal and peak levels of serum immunoreactive insulin (IRI $I_{b}$ and IRI $_{p}$, resp.) in the oral glucose tolerance test (OGTT), and obesity indices. The serum GH levels as well as plasma SM-C levels in the group with decreased serum high density lipoprotein-cholesterol (HDL-C) differed greatly from those of the normal HDL-C group. However, there was no significant difference in either serum GH or plasma SM-C between groups with and without metabolic abnormality of any other lipid examined.

After the operation, the basal levels of serum GH and plasma SM-C decreased significantly. In conjunction with these changes, $P G_{p}$, serum IRI $I_{b}$, serum triglyceride (TG), non-esterified fatty acid (NEFA) and very low density lipoprotein (VLDL) decreased significantly. In contrast, serum HDL-C increased significantly. However, FPG, serum IRI $I_{p}$, obesity indices, serum total cholesterol (TC) and serum low density lipoprotein (LDL) showed no significant change.

There were no significant differences in the levels of any serum lipid either before or after surgery among the diabetic, borderline and normal types defined by the preoperative OGTT patterns. Atherogenic indices (AIs) decreased significantly and returned to normal postoperatively.

These results suggest that obesity or secondary diabetes is not a direct cause of hyperlipidemia in acromegaly. The prognosis of acromegaly is affected by arteriosclerotic complications. It is intriguing, therefore, that AIs were normalized by transsphenoidal SPA. Being rather a safe procedure, it can be performed without hesitation, aside from a conservative treatment.
\end{abstract}

\section{Received April 10, 1990}

A1l correspondence and reprint requests to: HIROYASU TSUCHIYA, M. D., Dept. of Epidemiology and Mass Examination for Cardio- vascular Diseases, The Center for Adult Diseases, Osaka, 1-3-3 Nakamichi Higashinari-ku, Osaka 537, Japan. 
The incidences of arteriosclerotic diseases (ASD) such as coronary arterial and cerebrovascular diseases are high in an acromegalic population, irrespective of age. These diseases are attributed to abnormal carbohydrate metabolism and hypertension which often complicate acromegaly (Wright et al., 1970 ; Shizume, 1980). Hyperlipidemia is also an important risk factor for ASD and many acromegalic patients have hyperlipemia (Nikkilä and Pelkonen, 1975 ; Takeda et al., 1982). The mechanism by which lipid metabolism is disordered in this disease has not been fully elucidated, although various theories have been advanced to explain its pathogenesis. For example, excess growth hormone (GH) promotes insulin secretion and accelerates triglyceride (TG) synthesis in the liver (Nikkilä and Pelkonen, 1975); the lypolytic action of GH elevates serum levels of nonesterified fatty acid (NEFA), which enhances the turnover of TG and increases its serum levels (Raben and Hollenberg, 1959; Rabinowitz et al., 1966) ; GH inhibits lipoprotein lipase (LPL) and hepatic TG lipase (HTGL) activities (Murase et al., 1980; Murase et al., 1981; Takeda et al., 1982; Asayama et al., 1984); and somatomedin, a GH mediator, promotes liposynthesis and inhibits lipolysis (Demura and Demura, 1982). It has been well documented that diabetic complication has some effects on the pathology of acromegaly. Like excess $\mathrm{GH}$, excess prolactin (PRL) was found in 20-60\% of acromegalics (Kameyama et al., 1980 ; Camanni et al., 1982; Kanie et al., 1983; Tsuchiya et al., 1985). Excess PRL may also affect lipid metabolism in acromegaly (Garrison and Scow, 1975 ; Aisaka, 1982; Botta et al., 1982; Demura and Demura, 1982).

Transsphenoidal selective pituitary adenomectomy (SPA) combined with bromocriptine administration is nowadays performed on acromegalic patients rather frequently. However, there are few reports detailing lipid metabolism before and after the operation. In this study we investigated preand postoperative lipid metabolism in acromegalic subjects.

\section{Materials and Methods}

\section{Subjects}

Sixteen acromegalic patients aged 21-60 years (mean $\pm \mathrm{SD}, 45.0 \pm 11.9$ years) participated in this study. They consisted of 7 males (46.9 \pm 10.4 years) and 9 females (43.6 \pm 13.4 years). None of them had a hereditary background of hyperlipemia. SPA was performed on all patients via a transsphenoidal route. Basal levels of serum GH, plasma somatomedin-C (SM-C) and serum lipids were determined before and after SPA.

\section{Tolerance tests and stimulation tests}

Oral glucose tolerance tests (OGTT), thyrotropin releasing hormone (TRH) tests and luteinizing hormone releasing hormone (LHRH) tests were done before and 2-5 weeks after surgery. These three kinds of tests were conducted on separate days, each starting at $0600 \mathrm{~h}$ after an overnight fast, except that the patient was allowed to take water ad libitum. During each test the patient was allowed to rest comfortably, but was not allowed to take food or sleep. An indwelling needle was put in an arm vein, and then $75 \mathrm{~g}$ glucose (Trelan-G; Shimizu Pharmaceutical Co. or Takeda Chemical Industries, Osaka, Japan) was administered orally for the OGTT, and $0.5 \mathrm{mg}$ TRH (Protirelin; Tanabe Seiyaku Co., Osaka, Japan) and $0.1 \mathrm{mg}$ LHRH (Gonadorelin Diacetate; Tanabe Seiyaku Co.) were injected into the contralateral arm vein simultaneously for the TRH test or the LHRH test. Blood samples were obtained via the indwelling needle immediately before $(0 \mathrm{~min})$, and $30,60,90,120,150$ and $180 \mathrm{~min}$ after glucose ingestion for glucose and immunoreactive insulin (IRI) measurement; 0, 15, 30, 60, 90, 120 and $180 \mathrm{~min}$ after the injection of TRH for $\mathrm{GH}$ measurement; and $0,30,60,90$ and $120 \mathrm{~min}$ after the injection of LHRH for GH measurement. Sodium fluoride-treated plasma samples for glucose measurement and serum samples for IRI and GH measurement were separated promptly and were stored at $-20^{\circ} \mathrm{C}$ until assay. 


\section{Assays}

Plasma glucose was measured by a glucoseoxidase method on a Beckman II Glucose Analyzer (Beckman Instruments, Fullerton, Calif., U. S. A.). The normal range of fasting plasma glucose (FPG) as determined by this method was $70-110 \mathrm{mg} / \mathrm{dl}$.

Serum GH was measured by double antibody radioimmunoassay (RIA) with the $\mathrm{HGH} \cdot \mathrm{RIA}$ KIT (Dainabot Radioisotope Laboratories, Tokyo, Japan). The lower limit of detection was $1.0 \mathrm{ng} / \mathrm{ml}$. The intra- and interassay coefficients of variation $(\mathrm{CV})$ were $3.0 \%$ at $13.3 \mathrm{ng} / \mathrm{ml}$ and $4.8 \%$ at $7.9 \mathrm{ng} / \mathrm{ml}$, respectively. The overall recovery was $107.5 \pm 11.6 \%$ (mean $\pm \mathrm{SD}$ ). The normal range of overnight fasting, resting levels of $\mathrm{GH}$ was $0-5.0 \mathrm{ng} / \mathrm{ml}$.

SM-C was measured in EDTA $\mathrm{Na}_{2}$-treated plasma by double antibody RIA with the SM-C RIA Kit (Nichols Institute Diagnostics, San Juan Capistrano, Calif., U. S. A.). The lower detection limit was $5.0 \mathrm{mIU} / \mathrm{ml}$. The intra- and interassay $\mathrm{CV}$ were $7.2 \%$ at $2.1 \mathrm{IU} / \mathrm{ml}$ and $13.3 \%$ at $1.6 \mathrm{IU} / \mathrm{ml}$, respectively. The overall recovery was $99.2 \pm 9.2 \%$. The antiserum for SM-C showed virtually no cross-reactivity with human GH (hGH), human PRL (hPRL), human thyroid stimulating hormone (hTSH), porcine proinsulin, porcine insulin or porcine glucagon. The normal range determined in 22 healthy adults was 0.3$2.5 \mathrm{IU} / \mathrm{ml}$ (Tsuchiya et al., 1985).

Serum IRI was measured by solid phase RIA with the PHADEBAS INSULIN TEST (Pharmacia Diagnostics, Uppsala, Sweden). The sensitivity of the assay was $3.0 \mu \mathrm{U} / \mathrm{ml}$. The intra- and interassay $\mathrm{CV}$ were $3.7 \%$ at $15.1 \mu \mathrm{U} /$ $\mathrm{ml}$ and $7.3 \%$ at $6.5 \mu \mathrm{U} / \mathrm{ml}$, respectively. The overall recovery was $98.4 \pm 11.6 \%$. The normal range of overnight fasting, resting levels of serum IRI was $0-20.0 \mu \mathrm{U} / \mathrm{ml}$.

Serum total cholesterol (TC), TG, NEFA, low density lipoprotein (LDL) and very low density lipoprotein (VLDL) were measured by an enzymatic method (Allain et al., 1974;

Table 1. Levels of serum lipids, serum GH and plasma SM-C and incidences of metabolic abnormalities of lipids in 16 acromegalic patients

\begin{tabular}{|c|c|c|c|c|c|c|}
\hline Group & Serum lipid & $\begin{array}{l}\text { Normal range } \\
\text { or } \mu \mathrm{Eq} / 1)^{\mathrm{c}}\end{array}$ & $\underset{(\mathrm{ng} / \mathrm{ml})}{\text { Serum GH }}$ & $\begin{array}{c}\text { Plasma SM-C } \\
(\mathrm{IU} / \mathrm{ml})\end{array}$ & $\mathrm{N}={ }^{\mathrm{a}}$ & $\begin{array}{c}\text { Incid }^{\mathrm{b}} \\
(\%)\end{array}$ \\
\hline Hyperchol $^{\mathrm{d}}$ & $258.6 \pm 19.7$ & & $32.9 \pm 8.8$ & $6.2 \pm 1.3$ & 5 & \\
\hline Normochol $^{\mathrm{d}}$ & $169.6 \pm \quad 4.2$ & $160.0-210.0$ & $91.6 \pm 25.1$ & $6.2 \pm 1.0$ & 11 & 31.3 \\
\hline Hypertrigly & $259.4 \pm 36.1$ & $42.0-169.0^{\mathrm{f}}$ & $37.5 \pm 9.4$ & $7.0 \pm 1.4$ & 6 & 37.5 \\
\hline Normotrigly $^{e}$ & $114.5 \pm 7.8$ & $(35.0-136.0)$ & $94.8 \pm 27.5$ & $5.7 \pm 0.9$ & 10 & \\
\hline High NEFA & $698.1 \pm 47.3$ & $100.0-540.0$ & $112.1 \pm 32.5$ & $5.7 \pm 1.6$ & 4 & 25.0 \\
\hline Normal NEFA & $373.9 \pm 36.8$ & & $60.4 \pm 21.7$ & $6.4 \pm 0.9$ & 12 & \\
\hline High LDL & $869.0 \pm 117.0$ & $250.0-600.0$ & $35.5 \pm 12.8$ & $6.0 \pm 2.3$ & 3 & 20.0 \\
\hline $\begin{array}{l}\text { Norma1 LDL } \\
\text { High VLDL }\end{array}$ & $\begin{array}{l}466.5 \pm 19.7 \\
203.0 \pm 52.0\end{array}$ & & $\begin{array}{l}87.8 \pm 23.3 \\
46.1 \pm 24.4\end{array}$ & $\begin{array}{l}6.1 \pm 0.9 \\
5.1 \pm 2.3\end{array}$ & $\begin{array}{r}12 \\
2\end{array}$ & \\
\hline $\begin{array}{l}\text { Normal VLDL } \\
\text { Low HDL-C }\end{array}$ & $\begin{array}{ll}78.4 \pm & 7.1 \\
29.6 \pm & 1.6\end{array}$ & $0-150.0$ & $\begin{array}{c}82.1 \pm 22.0 \\
105.6 \pm 27.2 *\end{array}$ & $\begin{array}{l}6.2 \pm 0.9 \\
7.6 \pm 0.9 * *\end{array}$ & $\begin{array}{r}13 \\
8\end{array}$ & 13.3 \\
\hline Norma1 HDL-C & $39.4 \pm \quad 0.7$ & $\begin{array}{r}35.0-58.0^{\mathrm{f}} \\
(38.0-65.0)\end{array}$ & $45.0 \pm 23.8^{*}$ & $4.4 \pm 1.1^{* *}$ & 7 & 53.3 \\
\hline
\end{tabular}

Each value represents the mean \pm SE.

$\mathrm{a}$ : No. of patients. $\quad \mathrm{b}$ : Incidences of metabolic abnormalities of lipids. $\mathrm{c}$ : Units for all parameters except NEFA are mg/dl. d: Hyper- or normocholesterolemic group. e : Hyper or normotriglyceridemic group. $f$ : Normal ranges in males followed by those in females in parentheses.

*: Significantly different $(\mathrm{p}<0.005)$. **: Significantly different $(\mathrm{p}<0.05)$. 
Hayashi and Ogawa, 1976), a lipoprotein lipaseglycerol kinase-pyruvate kinase-lactate dehydrogenase method (Bucolo et al., 1975), an acyl CoA synthetase-acyl CoA oxidase-peroxidase method (Takahashi et al., 1975), heparin-calcium nephelometry (Koide, 1975) and heparin-calcium nephelometry (Koide et al., 1975), respectively, on a TBA-80S Auto Analyzer (Toshiba Instruments, Tokyo, Japan). Serum high density lipoprotein-cholesterol (HDL-C) was measured by a precipitation method with a heparin- $\mathrm{CaCl}_{2}$ series reagent (Liedke et al., 1978; Ash and Hentschel, 1978; Fujita et al., 1980) on an Auto Analyzer II (Technicon Instruments, New York, U. S. A.). The normal ranges of these lipids are shown in Table 1.

In order to reduce interassay variations, all samples from each individual subject were analyzed at the same time in each assay.

\section{Calculations and statistical analyses}

Each value is expressed as the mean \pm SD or mean $\pm \mathrm{SE}$. The standard weight $\left(\mathrm{W}_{\mathrm{s}}\right)$ was calculated by Broca's innovated method $\left[\mathrm{W}_{\mathrm{s}}=\right.$ (height in $\mathrm{cm}-100) \times 0.9 \mathrm{~kg}$. The obesity index was calculated by the formula, obesity index (\%) $=\left(\right.$ weight $\left./ \mathrm{W}_{\mathrm{s}}\right) \times 100$. The normal range of this index was $90-110 \%$. Student's two-tailed, paired t-test was used to compare pre- and postoperative data in the individual cases and Student's two-tailed, unpaired t-test to compare determinations between groups. Wilcoxon's test was employed to assess the significance of differences in the serum GH concentration between groups with and without an abnormality of any serum lipid. An $\alpha$ probability less than 0.025 was accepted as an indication of a significant difference.

\section{Results}

The incidences of lipid metabolic disorders in the present series are shown in Table 1. None of the 7 males had hypercholesterolemia, while its incidence was $55.6 \%(5 / 9)$ in the female group. The incidence of hypertriglyceridemia was $14.3 \%$ $(1 / 7)$ in the male group and $55.6 \%(5 / 9)$ in the female group. A study of phenotypes as assessed merely from $\mathrm{TC} / \mathrm{TG}$ ratios according to the WHO classification of hyperlipemia (Beaumont et al., 1970) revealed one case of type $\mathrm{II}_{\mathrm{a}}$ and another of type $\mathrm{II}_{\mathrm{b}}$, but the phenotypes of the remaining cases could not be identified.

None of the basal levels of serum GH and plasma SM-C, FPG levels, peak plasma glucose $\left(\mathrm{PG}_{\mathrm{p}}\right)$ levels in the OGTT, basal and peak serum IRI (serum IRI $_{b}$ and IRI $_{p}$, resp.) levels in the OGTT, and obesity indices were correlated with any serum lipid. Serum GH and plasma SM-C were significantly different only between the low and normal HDL-C groups and not between a pair of groups, one with and the other without metabolic disorder of any other lipid examined (Table 1).

The basal levels of serum GH and plasma SM-C, which had been markedly elevated to $73.3 \pm 18.6 \mathrm{ng} / \mathrm{ml}$ (mean $\pm \mathrm{SE}$ ) and $6.2 \pm$ $0.8 \mathrm{IU} / \mathrm{ml}$, respectively, before surgery, decreased significantly to $3.3 \pm 0.7 \mathrm{ng} / \mathrm{ml}$ and $1.2 \pm 0.3 \mathrm{IU} / \mathrm{ml}, \quad$ respectively $\quad(\mathrm{p}<0.001)$. Postoperative decreases in serum $\mathrm{GH}$ and plasma SM-C were seen in all individuals. In 13 patients, they returned to normal $(<5.0 \mathrm{ng} / \mathrm{ml}$ and $<2.5 \mathrm{IU} / \mathrm{ml}$, resp.). Furthermore, the $\mathrm{GH}$ responses to the postoperative TRH and LHRH tests were normal, even in those in whom GH had responded abnormally to these tests before surgery. The peak levels of $\mathrm{GH}$ in response to TRH decreased significantly from the preoperative levels of $298.1 \pm 91.7$ to $11.9 \pm 2.9 \mathrm{ng} / \mathrm{ml}$ postoperatively $(\mathrm{p}<0.006)$ and those in response to LHRH from 149.9 \pm 60.8 to $6.6 \pm 3.0 \mathrm{ng} / \mathrm{ml}(\mathrm{p}<0.03)$ (Fig. 1).

According to the $75 \mathrm{~g}$ OGTT criteria established by the Japan Diabetes Society (Kosaka et al., 1982), 4 cases were classified as the diabetic type, 9 as the borderline type and the remaining 3 as the normal type before surgery. Out of the 4 diabetic type cases, 2 still gave a diabetic pattern of response to the postoperative OGTT, but one case changed into the borderline type and the last one into the 

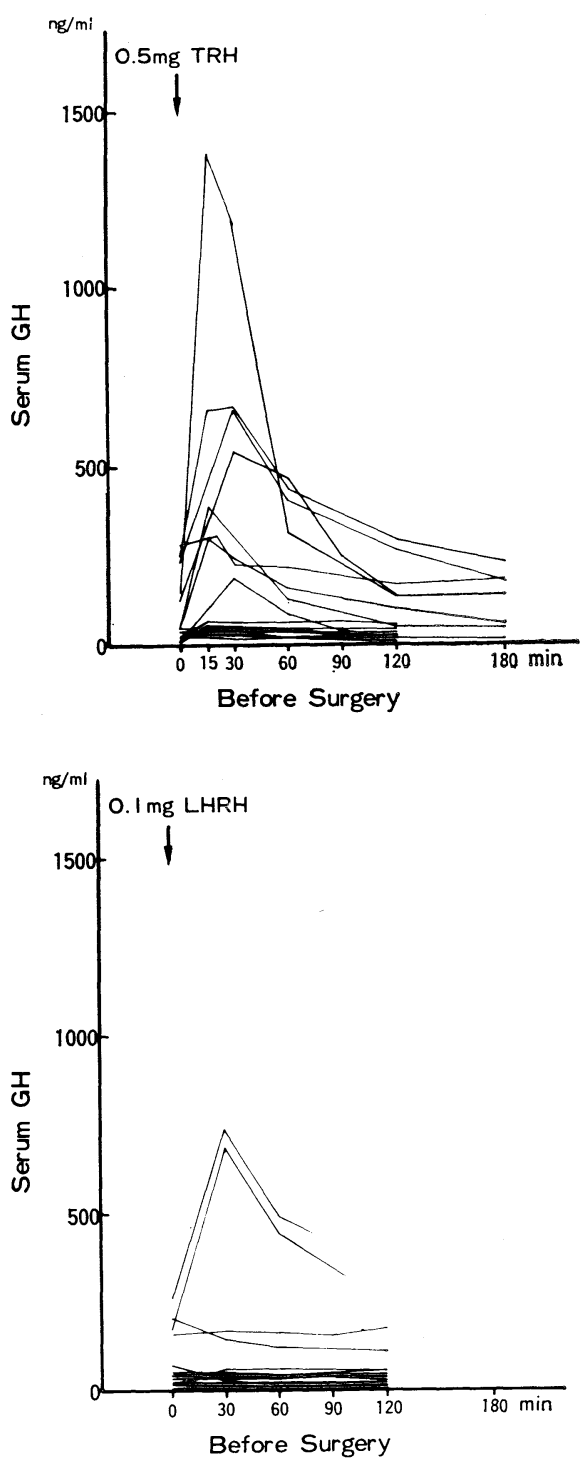

$0.5 \mathrm{mg} \mathrm{TRH}$

1

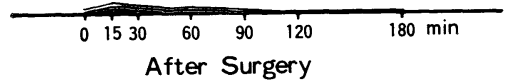

$0.1 \mathrm{mg}$ LHRH

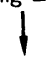

Fig. 1. Responses of GH to intravenous TRH (upper panels, $n=16$ ) and LHRH injection (lower panels, $n=15$ ) in acromegalic patients before and after surgery.

normal type after surgery. All but one borderline type case had a normal pattern after surgery. The exceptional case could not be examined postoperatively. Of the 3 normal type cases, one responded normally to the postoperative test as well, but another changed into the borderline type after surgery. The last case could not be examined postoperatively. The postoperative FPG levels $(93.4 \pm 5.8 \mathrm{mg} / \mathrm{dl}$, mean $\pm \mathrm{SE})$ were not significantly different from the preoperative levels $(144.9 \pm 26.7 \mathrm{mg} / \mathrm{dl})$ in 14 patients, although they showed a tendency to decrease after surgery. $P_{p}$ de- 
creased significantly after surgery $(168.9 \pm$ 20.8 vs $254.2 \pm 35.1 \mathrm{mg} / \mathrm{dl}, \mathrm{p}<0.02)$ in the 14 patients (Fig. 2, upper panels). Serum
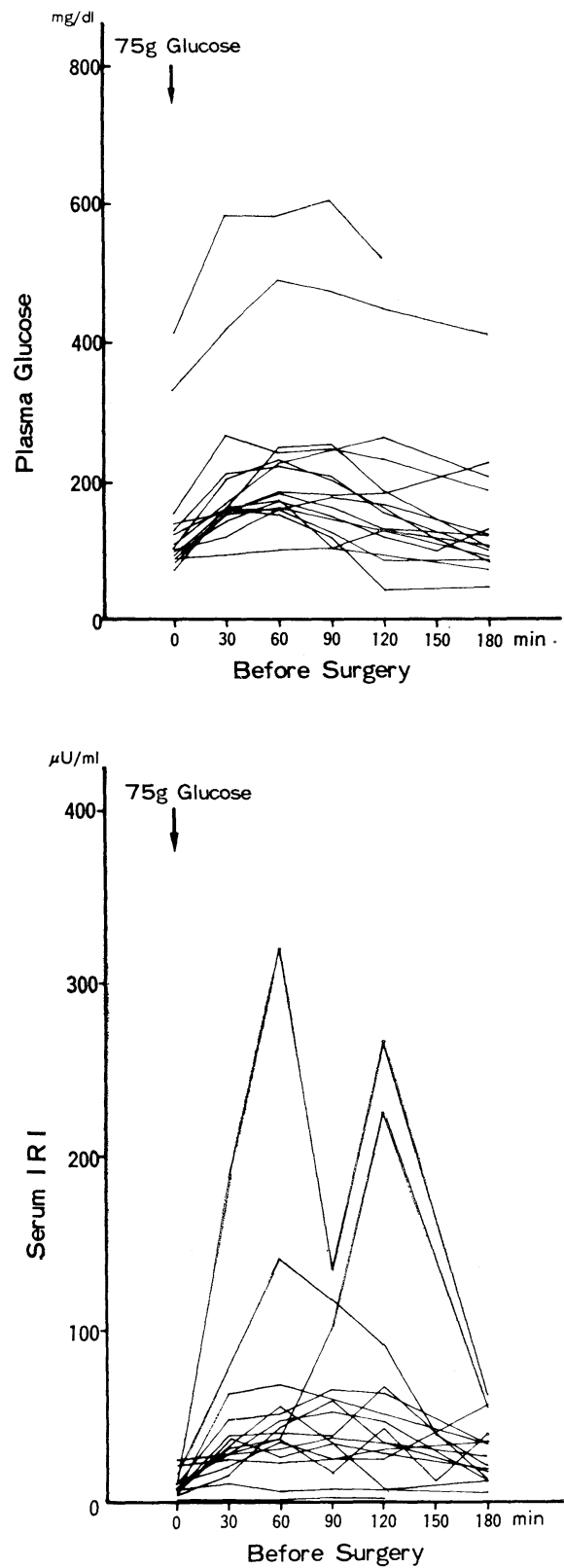

IRI $_{\mathrm{b}}$ decreased significantly after surgery $(6.1 \pm 1.1$ vs $11.2 \pm 1.7 \mu \mathrm{U} / \mathrm{ml}, \quad \mathrm{p}<0.003)$. Serum $I_{R I}$ tended to decrease after surgery

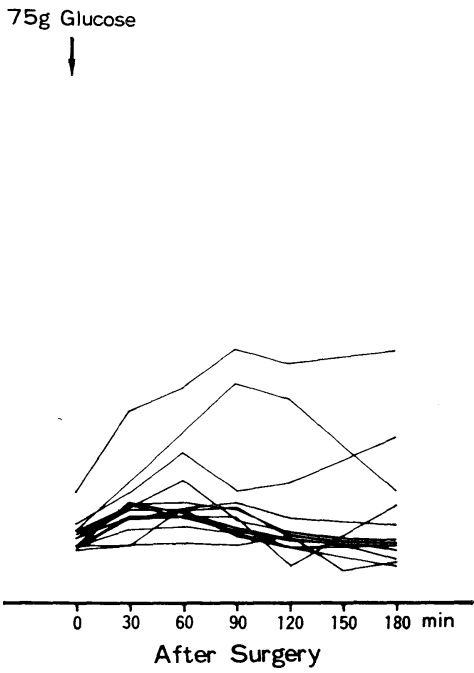

$75 \mathrm{~g}$ Glucose<smiles>C[As]1CC[As]1</smiles>

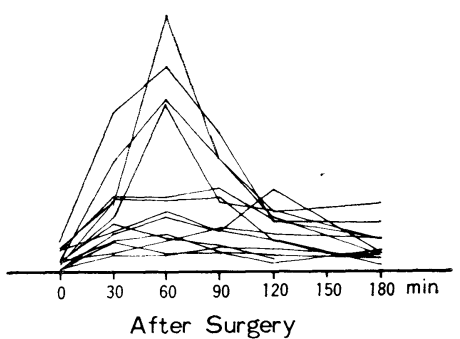

Fig. 2. Responses of glucose (upper panels, $n=14$ ) and IRI (lower panels, $\mathrm{n}=14$ ) to oral glucose administration in acromegalic patients before and after surgery. 

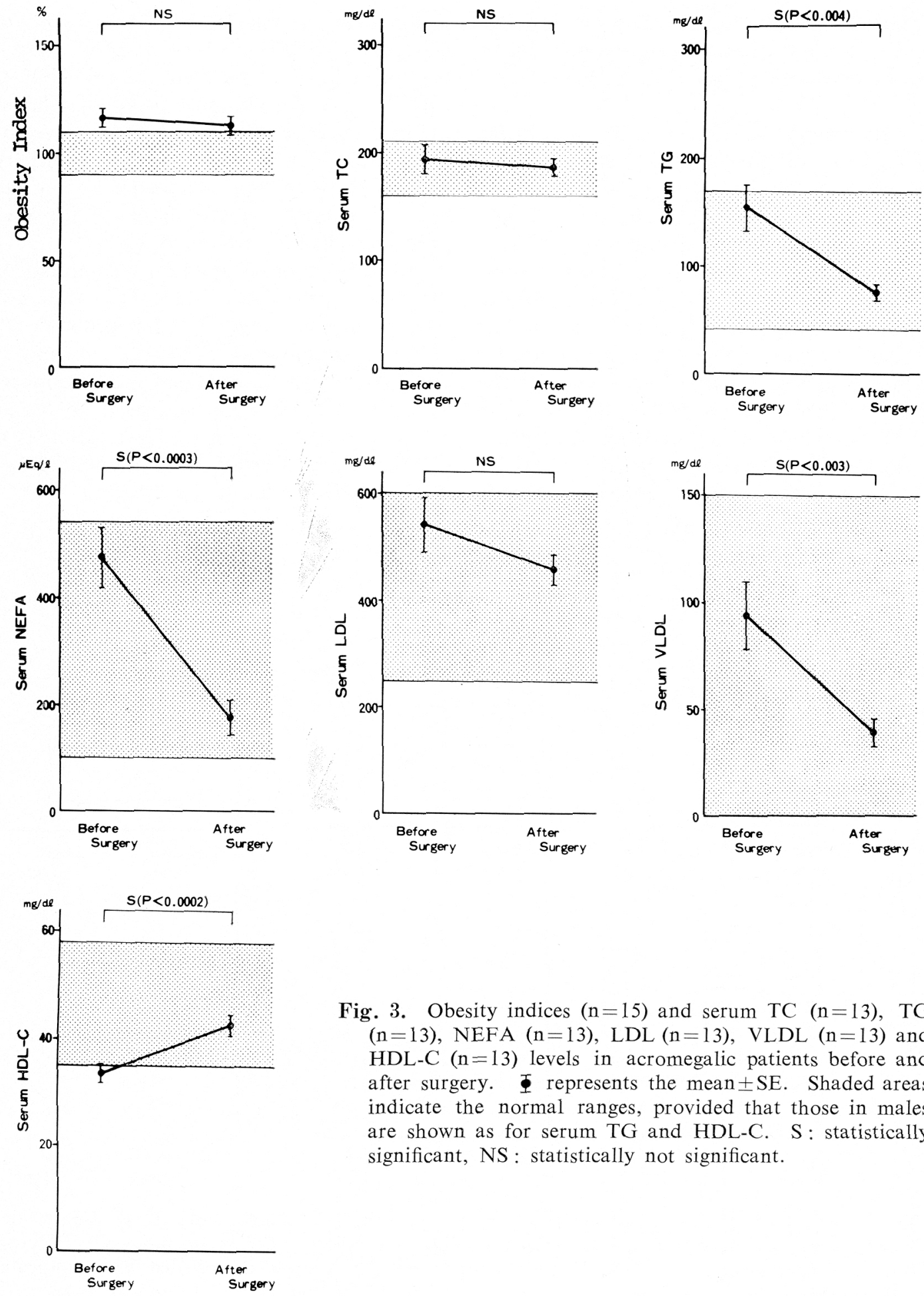

Fig. 3. Obesity indices $(n=15)$ and serum TC $(n=13)$, TG $(n=13)$, NEFA $(n=13)$, LDL $(n=13)$, VLDL $(n=13)$ and HDL-C $(n=13)$ levels in acromegalic patients before and after surgery. $\Phi$ represents the mean \pm SE. Shaded areas indicate the normal ranges, provided that those in males are shown as for serum TG and HDL-C. S: statistically significant, NS: statistically not significant. 
(from $52.5 \pm 11.7$ to $83.8 \pm 23.5 \mu \mathrm{U} / \mathrm{ml}$ ), but no significant difference was present between the two determinations (Fig. 2, lower panels).

The obesity indices, serum TC and serum LDL were apt to decrease postoperatively, though the changes were not significant. Serum TG, NEFA and VLDL levels decreased significantly in 13 patients (from 153.6 \pm 22.1 to $75.6 \pm 7.9 \mathrm{mg} / \mathrm{dl}, \mathrm{p}<0.004$; from $474.0 \pm 54.5$ to $174.8 \pm 34.5 \mu \mathrm{Eq} / 1, \mathrm{p}<0.0003 ;$ and from $94.2 \pm 15.9$ to $39.4 \pm 6.8 \mathrm{mg} / \mathrm{dl}$, $\mathrm{p}<0.003$, resp.). In contrast, serum HDL$\mathrm{C}$ increased significantly from $33.5 \pm 1.8$ to $42.7 \pm 2.0 \mathrm{mg} / \mathrm{dl} \quad(\mathrm{n}=13, \mathrm{p}<0.0002)$ (Fig. 3).

However, the surgery-induced decrement in serum $\mathrm{GH}, \mathrm{PG}_{p}$ or serum $\mathrm{IRI}_{\mathrm{b}}(-\Delta \mathrm{GH}$, $-\Delta \mathrm{PG}_{\mathrm{p}}$ or $-\Delta \mathrm{IRI}_{\mathrm{b}}$, resp.) had no significant correlation with the surgery-induced de- crement in serum TG, NEFA or VLDL $(-\triangle \mathrm{TG},-\triangle \mathrm{NEFA}$ or $-\Delta \mathrm{VLDL}$, resp.), or with the increment in serum HDL-C (AHDL-C). Furthermore, no significant differences were recognized in the level of any serum lipid before or after surgery among the three types (diabetic, borderline, normal) defined on the basis of the preoperative OGTT patterns (Fig. 4).

Eleven patients could be examined for the atherogenic index $[\mathrm{AI}=(\mathrm{TC}-\mathrm{HDL}-\mathrm{C}) /$ HDL-C, normal range <4.0] (Gordon et al., 1977 ; Yamamoto et al., 1982; Mizuno et al., 1984) both before and after surgery. Their AIs, which were increased to $4.8 \pm$ 1.5 (mean $\pm \mathrm{SD}$ ) preoperatively, decreased significantly and returned to normal $(3.7 \pm$ $0.9, \mathrm{p}<0.009)$ after surgery.
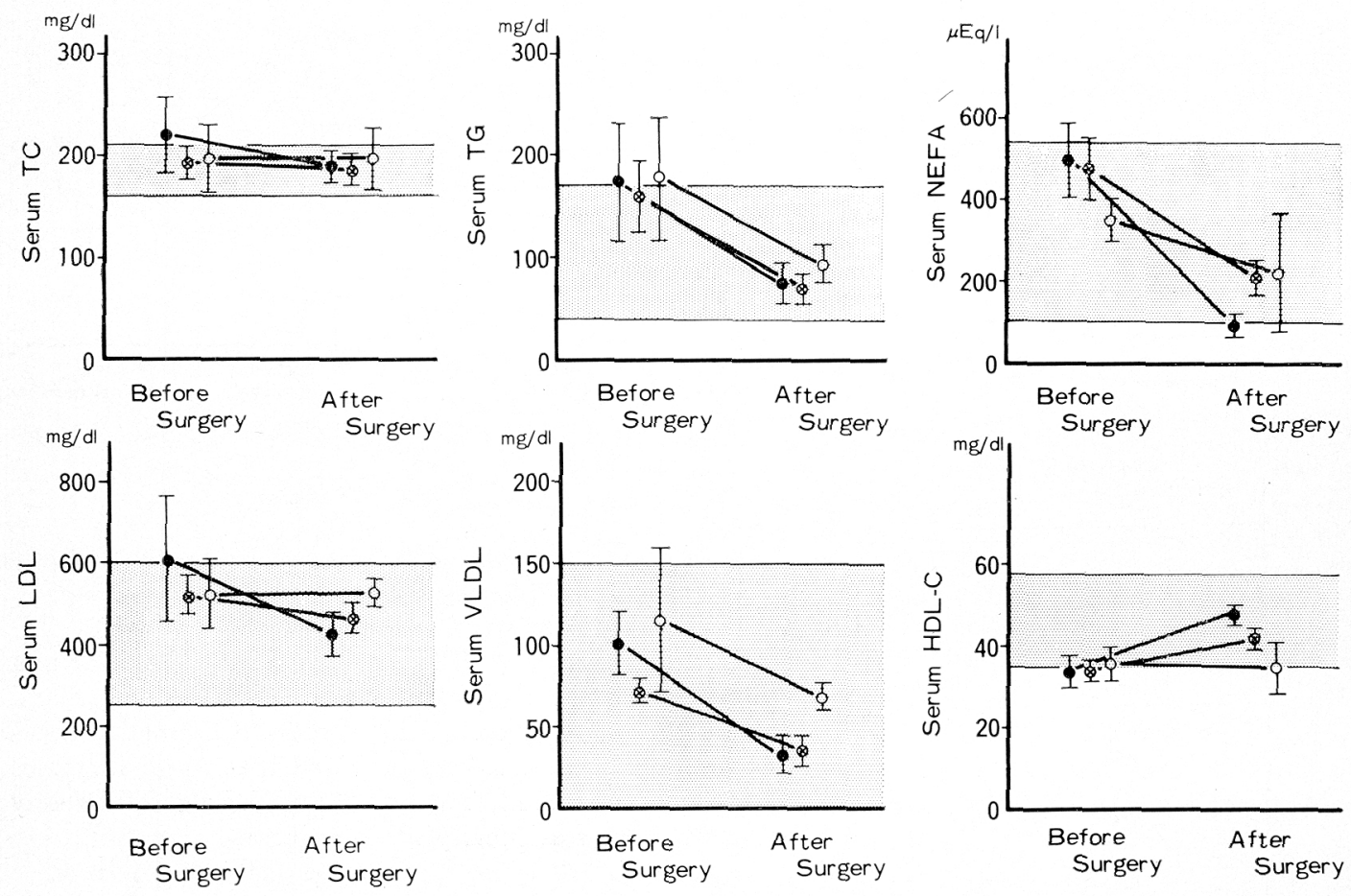

Fig. 4. Pre- and postoperative levels of serum lipids in the diabetic $(\bullet, n=4)$, borderline $(\Phi, \mathrm{n}=9)$ and normal $(\bigcirc, \mathrm{n}=3$ ) types (defined according to the preoperative OGTT profiles) of acromegaly. Each $\mathbf{\Phi}$, $\Phi$ and $\Phi$ represents the mean \pm SE. Shaded areas indicate the normal ranges, provided that those in males are shown for serum TG and HDL-C. 


\section{Discussion}

Nikkilä and Pelkonen (1975) detected hypercholesterolemia in $11 \%$ of acromegalic patients and hypertriglyceridemia in $32 \%$ and $19 \%$ of male and female patients, respectively. Takeda et al. (1982) found one or another form of hyperlipemia in $62.5 \%$ of acromegalic patients. The incidence of hyperlipemia, which was defined as an increase in the concentration of any lipid in serum, was as high as $75.0 \%(12 / 16)$ in the present series. According to the WHO phenotype classification of hyperlipemia, type $\mathrm{II}_{\mathrm{a}}$ was recognized in only one of our 16 patients with acromegaly and type $\mathrm{II}_{\mathrm{b}}$ in another. Nikkilä and Pelkonen (1975) found type IV at a much higher frequency than the generally expected frequency $(19.6 \%$ vs $7.3 \%)$ in acromegaly.

In our acromegalic subjects the level of no lipid in serum correlated with serum $\mathrm{GH}$, plasma SM-C, FPG, $\mathrm{PG}_{\mathrm{p}}$, serum $\mathrm{IRI}_{\mathrm{b}}$, $\mathrm{IRI}_{\mathrm{p}}$ or obesity indices. These observations were in good accord with an earlier report (Nikkilä and Pelkonen, 1975). Takeda et al. (1982) stated that serum GH levels were significantly higher in acromegalic patients with hypercholesterolemia than in those without it. However, the present study demonstrated a significant difference in serum $\mathrm{GH}$ concentration only between the low and normal HDL-C groups and never between a group with a metabolic disorder of any other lipid and its counterpart.

The normalization of the basal level of serum GH and its response to TRH and LHRH suggested that pituitary adenomas could be almost completely extirpated in all of our patients (Hoyte and Martin, 1975 ; Faglia et al., 1978). Obesity or diabetes is said to not contribute to the occurrence of hyperlipemia in acromegaly (Nikkilä and Pelkonen, 1975 ; Takeda et al., 1982). Our findings were compatible: Although serum lipid levels were changed significantly by surgery, obesity indices were not. Therefore, obesity is unlikely to be a direct cause of hyperlipemia. On the other hand, transsphenoidal SPA improved plasma glucose response to the OGTT and caused significant decreases in $\mathrm{PG}_{\mathrm{p}}$ and serum $\mathrm{IRI}_{\mathrm{b}}$ in the OGTT as well as significant changes in serum lipid levels. These raised the possibility of diabetes having some relation to hyperlipemia. However, no significant differences were found in any serum lipid before or after surgery among the three types defined according to the preoperative OGTT profiles. Therefore, the direct etiologic role of diabetes in hyperlipemia seems to be denied.

$\mathrm{GH}$ has been reported to inhibit both LPL and HTGL not only in vivo (Murase et al., 1980 ; Takeda et al., 1982 ; Asayama et al., 1984) but also in vitro (Murase et al., 1981). Probably for this reason, many acromegalic patients have hyperlipemia. In this study SPA induced significant changes in serum lipid levels and significant decreases in serum GH and plasma SM-C levels. A reasonable inference from this fact is that GH and/or SM-C might play an etiologic role in the derangement of lipid metabolism in acromegaly.

In our acromegalic patients AIs decreased significantly and returned to normal after surgery. It is generally accepted that increased mortality from acromegaly is largely due to frequent arteriosclerotic complications. In this connection, it was reported that mortality was significantly lower in a group treated for ASD than in an untreated group (Wright et al., 1970). Since transsphenoidal SPA and bromocriptine administration can be conducted relatively safely, we think that they should be tried positively in the management of acromegalic patients. 


\section{Acknowledgements}

The authors express their deep gratitude to Prof. Kiyoshi Miyai, M. D. (Central Laboratory for Clinical Investigation, Osaka University Medical School, Osaka, Japan) for measuring serum lipids, to Ms. Yayoi Hayakawa for processing the data, and to Prof. Charles A. Nugent, M. D. (Endocrine Section, College of Medicine, University of Arizona, Tucson, Arizona, U. S. A.) for giving us some valuable suggestions as well as for reading the manuscript. This work was supported in part by research grants from the Ministry of Education, Science and Culture and the Ministry of Health and Welfare of Japan.

\section{References}

Aisaka, K. (1982). Effects of prolactin on lipid metabolism. Acta Obst. Gynaec. Jpn. 34, 559568.

Allain, C. C., L. S. Poon, C. S. G. Chan, W. Richmond and P. C. Fu (1974). Enzymatic determination of total serum cholesterol. Clin. Chem. 20, 470-475.

Asayama, K., S. Amemiya, S. Kusano and K. Kato (1984). Growth hormone-induced changes in postheparin plasma lipoprotein lipase and hepatic triglyceride lipase activities. Metabolism 33, 129-131.

Ash, K. O. and W. M. Hentschel (1978). High density lipoproteins estimated by an enzymatic cholesterol procedure, with a centrifugal analyzer. Clin. Chem. 24, 2180-2184.

Beaumont, J. L., L. A. Carlson, G. R. Cooper, Z. Fejfar, D. S. Fredrickson and T. Strasser (1970). Classification of hyperlipidaemias and hyperlipoproteinaemias. Bull. WHO 43, 891915.

Botta, R. M., M. Donatelli, A. Zampardi, T. Incandela, P. Valenza, V. Albano and G. Bompiani (1982). Study on maternal, fetal and amniotic prolactin in gestational diabetic women at term. Acta Diabet. Lat. 19, 275280.

Bucolo, G., R. McCroskey and N. Whittaker (1975). Lipase triggered kinetic assay of serum triglycerides. Clin. Chem. 21, 424-426.

Camanni, F., F. Massara, M. Santia, G. M. Molinatti and E. E. Müller (1982). Impaired prolactin! responsiveness to dopamine antagonists in acromegaly. Metabolism 31, 1090-1095.

Demura, H. and R. Demura (1982). Several factors involved in carbohydrate metabolism regulatory system: pituitary hormone. Jpn. J. Clin. Med. 40, 315-320.

Faglia, G., A. Paracchi, C. Ferrari and P. BeckPeccoz (1978). Evaluation of the results of trans-sphenoidal surgery in acromegaly by assessment of the growth hormone response to thyrotrophin-releasing hormone. Clin. Endocrinol. 8, 373-380.

Fujita, S., I. Furukawa, K. Arisue, K. Kohda, C. Hayashi, M. Kawaguchi, T. Sodeyama and O. Hayashi (1980). Automated estimation of HDL-cholesterol by continuous ultrafiltration system. Jpn. J. Clin. Chem. 9, 321-326.

Garrison, M. M. and R. O. Scow (1975). Effects of prolactin on lipoprotein lipase in crop sac and adipose tissue of pigeons. Am. J. Physiol. 228, 1542-1544.

Gordon, T., W. P. Castelli, M. C. Hjortland, W. B. Kannel and T. R. Dawber (1977). HDL as a protective factor against coronary heart disease: the Framingham study. Am. J. Med. 62, 707-714.

Hayashi, C. and Z. Ogawa (1976). The review and automation of enzymatic method for serum lipid determination. Jpn. J. Clin. Pathol. 24, 638-644.

Hoyte, K. M. and J. B. Martin (1975). Recovery from paradoxical growth hormone responses in acromegaly after transsphenoidal adenomectomy. J. Clin. Endocrinol. Metab. 41, 656-659.

Kameya, T., M. Tsumuraya, I. Adachi, K. Abe, K. Ichikizaki, S. Toya and R. Demura (1980). Ultrastructure, immunohistochemistry and hormone release of pituitary adenomas in relation to prolactin production. Virchows Arch. [Pathol. Anat.] 387, 31-46.

Kanie, N., N. Kageyama, A. Kuwayama, T. Nakane, M. Watanabe and A. Kawaoki (1983). Pituitary adenomas in acromegalic patients: an immunohistochemical and endocrinological study with special reference to prolactinsecreting adenoma. J. Clin. Endocrino!. Metab. 57, 1093-1101.

Koide, A., T. Kawai and N. Kubota (1975). Analysis of serum lipoproteins by precipitation with heparin and calcium ions. Jpn. J. Clin. Pathol. [Suppl.] 21, 82-91.

Kosaka, K., Y. Akanuma, Y. Goto, A. Hakura, 
Y. Hirata, R. Kawate, T. Kuzuya, G. Mimura, H. Nakayama, N. Sakamoto and Y. Shigeta (1982). Report of committee on diagnosis of diabetes mellitus. Jpn. J. Diabetes 25, 859866.

Liedtke, R. J., B. Busby and J. D. Batjer (1978). Use of the Du Pont aca to measure cholesterol in high-density lipoprotein fractions prepared by the heparin $/ \mathrm{Mn}^{2+}$ precipitation method. Clin. Chem. 24, 161-165.

Mizuno, O., T. Yokoyama and N. Tsutsumi (1984). The changes of serum total cholesterol, HDL-cholesterol and atherogenic index in postpartum. Acta Obst. Gynaec. Jpn. 36, 25932597.

Murase, T., N. Yamada and F. Matsuzaki (1981). The in vitro effect of growth hormone on adipose tissue lipoprotein lipase in rats. Life Sci. 28, 199-201.

Murase, T., N. Yamada, N. Ohsawa, K. Kosaka, S. Morita and S. Yoshida (1980). Decline of postheparin plasma lipoprotein lipase in acromegalic patients. Metabolism 29, 666672.

Nikkilä, E. A. and R. Pelkonen (1975). Serum lipids in acromegaly. Metabolism 24, 829838.

Raben, M. S. and C. H. Hollenberg (1959). Effect of growth hormone on plasma fatty acids. J. Clin. Invest. 38, 484-488.

Rabinowitz, D., T. J. Merimee, J. A. Burgess and M. B. Baltimore (1966). Growth hormoneinsulin interaction. Diabetes 15, 905-910.

Shizume, K. (1980). Report of research on the actual condition of acromegaly and pituitary gigantism. In : Annual Report of the Study Committee on Hypothalamopituitary Diseases (Public Health Bureau, Ministry of Health and Welfare of Japan ed.), Tokyo, pp. 15-24.

Takahashi, Z., K. Fujii and C. Hayashi (1975). An approach to develop a new enzymatic method for determination of free fatty acid: preliminary report. Jpn. Clin. Chem. 4, 179185.

Takeda, R., R. Tatami, K. Ueda, H. Sagara, H. Nakabayashi and H. Mabuchi (1982). The incidence and pathogenesis of hyperlipidaemia in 16 consecutive acromegalic patients. Acta Endocrinol. 100, 358-362.

Tsuchiya, H., T. Onishi, S. Takamoto, S. Imanaka, Y. Saitoh, H. Mogami, S. Mori, T. Uozumi and Y. Kumahara (1985). Prolactin secretion in acromegalic patients before and after selective adenomectomy. J. Clin. Endocrinol. Metab. 61, 104-109.

Tsuchiya, H., T. Onishi, S. Takamoto, S. Morimoto, K. Fukuo, S. Imanaka, H. Yamamoto, S. Yukawa, E. Koh, T. Sonoda, T. Koide, S. Mori and Y. Kumahara (1985). An acromegalic patient with recurrent urolithiasis. Endocrinol. Japon. 32, 851-861.

Wright, A. D., D. M. Hill, C. Lowy and T. R. Fraser (1970). Mortality in acromegaly. $Q$. J. Med. 39, 1-16.

Yamamoto, Y., T. Mikawa, J. Sukai and T. Komazawa (1982). The study on HDL cholesterol and atherogenic index in normal Japanese men. J. Adult. Dis. 12, 165-169. 